\title{
(Nano)Technology for Managing Plant Organisms with the Help of Targeted Impact Using the Signals of the Physical Nature
}

\author{
Dedicated to the blessed memory of \\ Prof. Ruban Igor Nikolaevich \\ Karpachev V. V. ${ }^{*}$ Voropaeva N. L., Belonozhkina T. G., Naumov E. V. ${ }^{2}$, \\ Vasilev M. M. ${ }^{2}$, Petrov O. F. ${ }^{2}$, O. Figovsky ${ }^{1}$ \\ ${ }^{1}$ State Research Institute All-Russian Rapeseed Research Institute (ARRI), Lipetsk, Russia \\ Polymate Ltd.-INRC, Migdal Ha Emek, Israel \\ ${ }^{2}$ Joint Institute for High Temperatures of the Russian Academy of Sciences (JIHT RAS), Moscow \\ 398037, Russian Federation, Lipetsk c., Boyevoy proezd, 26, \\ Tel.IFax.: (4742) 34-63-61 \\ *E-mail address: bionanotex_I@mail.ru
}

\begin{abstract}
One of the major problems of agricultural production has been to improve the sowing qualities of seeds to increase yields of various crops. In this regard, of particular interest is the control technology of vegetable organisms by "address the impact of" signals of the physical nature. Plasma treatment of seeds influences the growth and development of the amaranth. The effectiveness of treatment depends on the exposure time of the exposure. The largest positive treatment effect of the plasma on the growth, development and yield of amaranth has been observed when the exposure 60 seconds, leading to increased yields.
\end{abstract}

Keywords: pre-treatment; seeds; plasma; amaranth; harvest: elicitors; (nano) chips; pre-sowing seed treatment; growth; development; the incidence of rape plants; the quantity and quality of their crop

\section{INTRODUCTION}

One of the major problems of agricultural production has been and now remains improvement of sowing qualities of seeds in order to increase the yield of various crops. In the new millennium, the global changes of soil and climatic conditions, the introduction and use of toxicants of different nature, as well as other adverse environmental factors, all set up an enormous stress on living organisms. In such conditions providing high and stable growth rates of agricultural production is possible only in case of the raising cultivation technologies on a new quality level. Switching to such technologies provides their maximum consistency with crop biological characteristics and agroecosystem environmental requirements. Living organisms and systems control methods using metabolic activators such as physiologically 
active substances, physical fields and etc. is currently one of the most promising directions in plant breeding [1-7].

In this regard, the technology of management of plant organisms through "targeted impact" using signals a physical nature is of particular interest. The efficiency of ultra-weak radiation can be explained by its regulatory effect and it can considered as signals for "switching" the program of physiological processes in the plant organism [2]. The most suitable approaches here are those where crops seeds are under impact.

Physical ways to stimulate biological processes during seed germination attract the attention of scientists for decades, due to their environmental friendliness; low energy and labor costs; excepting often toxic chemical plant protection and growth regulation means used in pre-sowing seed treatment. Moreover, these effects are considered as one of the main ways of nanobiotechnology applications in agriculture.

In this research area much attention is paid to the understanding of the effectiveness of plasma emissions applied in vivo to the seeds as living systems as an alternative to chemical and biological methods used in the preparation of seeds for sowing. [2] Plasma - a special state of matter (the fourth after solid, liquid and gaseous), characterized by the simultaneous existence of electrons, ions and neutral particles.

Biologically active plasma parameters have been characterized; theoretical approaches to plasma application have been studied; the attempts have been made to describe the theory of the interaction of plasma radiation and biological objects; we have also managed to identify in the laboratory, vegetative and field experiments the possibility of using and boosting the efficiency application of plasma for the treatment of seeds of different crops by increasing yield and also its quality (wheat, rye, barley, peas, lupine, soybean, corn, sunflower, rape, meadow clover, cocksfoot, meadow fescue, timothy grass, alfalfa volatile, melilot, garden radish, carrots, cabbage, lettuce, turnips, radish, cucumbers, tomatoes, sweet pepper, eggplant, beets, pumpkin, zucchini green, as well as other plant species); we have set out the basic requirements to agricultural plasmatrons and production units for the formation of physiologically active components of the plasma; we have come up with and tested in agricultural enterprise the recommendations on plasma technology for the cultivation of major crops [1-6].

Plasma treatment of seeds of different plants (cereals, oilseeds, vegetables, forage crops, ornamental plants) is being studied in a number of international research centers. It has been tested in different soil - climatic zones and a favorable impact on the seed material has been noted. The results showed that the germination and germination energy of seeds treated with plasma significantly increased, which gives a stable yield increase by $15-20 \%$ or more (up to $50 \%$ ), and improves the nutritional value of fruits and economically valuable plant organs due to the accumulation of higher amounts of proteins, sugars, organic acids, vitamin $\mathrm{C}$, trace elements and other nutrients.

Plasma treatment is characterized by a fungicidal and bactericidal effect, reducing seed infection by microscopic fungi, thereby increasing the resistance of seeds and plants to fungal and bacterial diseases. It thus increases seed and grain preservation under the conditions of prolonged storage. Plasma treatment makes the seed shell soft and permeable, which excludes the process of scarification of the seeds with hard shell. Seed plasma treatment technology is environmentally friendly due to eliminating the use of substances often toxic to humans, animals and the environment, such as various chemicals and other toxicants and hazardous emissions.

As V.I. Vernadsky underlined [quoted from 2], in plants, like the other organisms, evolution has developed certain adaptations for the perception of the effects of physical 
factors. And plasma radiation can be attributed to some of these impacts. However, the crucial aspects of this impact, in particular, the response of many plant species, including amaranth, are not fully explored.

The aim of our studies is to examine the efficiency of the plasma exposure (treatment with low temperature plasma of atmospheric pressure) of amaranth seeds as one of the forage crops with "fantastic opportunities", named by UNESCO experts as the major food crop in the XXI century.

\section{Results and Discussion}

A high biological productivity is the main advantage of amaranth compared to other forage crops. It is used as green fodder and also applied for making hay, silage. Also, cultivation of amaranth as a component of pastures is a promising direction. Amaranth biomass is easily converted into vitamin-grass powder with a protein content of $19-21 \%$, the introduction of which into the feed to adjust the protein content for all kinds of animals and growing groups in the amount of $10-15 \%$ at a low cost can significantly increase their productivity. Taking into consideration all the above stated, each new study aimed at increasing the yield of amaranth, is highly urgent and enhances the efficiency of its usage for different purposes.

The studies were conducted both in the laboratory and in field experiments. Amaranth seed lots were subjected to plasma treatment of various duration, and then were sown in Petri dishes and the soil. Stationary flow of nonisothermal plasma under atmospheric pressure was created by a microwave source with the oscillation frequency of $2.45 \mathrm{GHz}$. Low-temperature plasma generator is an axial electrode placed in a grounded metal cylinder with a pipe connection for supplying a working gas, argon. When pumping argon through the discharge gap with a rate of 5 liters per minute and magnetron power of 120 watt, a microwave plasma stream is being generated. The area treated with plasma flow in this case is 9 sq. $\mathrm{cm}$.

Compared with the control (when the seeds have been not treated with plasma on a special unit), the yield of amaranth crop grown from seeds subjected to plasma treatment with stimulating exposure within 60 seconds, increased by $17.0 \%$, whereas the exposure within $120 \mathrm{sec}$ - decreased the yield by $7.2 \%$ that allows us to identify the optimal plasma exposure time for seeds.

The cause of the noted positive effect, according to some researchers, is the activation of intracellular biochemical processes of seeds due to the plasma treatment, the increase of seed coat permeability, enhancing seed energy, mass, gas - and moisture exchange with the environment, which leads to increased energy germination, seed germination, plant growth and development at all the stages of ontogeny, and as a result, to the increased productivity.

\section{CONCLUSION}

Thus, the plasma treatment of seeds influences the growth and development of plant amaranth. The effectiveness of treatment depends on the exposure itself. The greatest positive impact of plasma treatment on amaranth growth, development and yield was recorded with the exposure within 60 seconds, resulting in an increase of yield by $17.0 \%$. 


\section{References}

[1] Gordeev A.M. Stimulation of biological processes in plant seeds by radiation from temperature plasma. Smolensk, 2007. Quot. from www.rusnor.org/pubs/library/6535.htm.

[2] Dutkiewich D.E. Substantiation of processing modes of permanent grasses seeds by radiations of low temperature helium plasma, 2005.- 201 pp. Quot. From http://www.dissercat.com/content/obosnovanie-rezhimov-obrabotki-semyanmnogoletnikh-trav-izlucheniyami-nizkotemperaturnoi-gel\#ixzz2s9vLFAyh.

[3] Arkhangelskaya Z.M. Whether is a seed treatment efficient in a hydrogen-plasma unit? Text: article. /Z.M. Arkhangelskaya, O.N. Aladina // Protection of plants, 1985.- №7.pp.21-22.

[4] Gomonov A.A. The effectiveness of the plasma treatment of seeds of winter rye. Text: Abstracts. / A.A. Gomonov // Science - for revival of agriculture in the XXI century. Velikie Luki, 2001. - pp. 85-87.

[5] Gomonov A.A. The effectiveness of the plasma treatment of amaranth seeds. Text: Article / A.A. Gomonov. // Science - for agricultural production and education. T. 2 Agronomy. Part I, Smolensk, 2004. - pp. 243-244.

[6] Plasma technology of seed treatment and plasma seeds. Quot. from urozhaynagryadka.narod.ru/plazma.htm.

[7] I. Ruban, N. Voropaeva, M.Sharipov, Magarshak Yu.B. Modern risks of the antropogenic influence on living spieces: nano-level fluctuations. In the book «Silicon Versus Carbon. Fundamental nanoprocesses, nanobiotechnology and risks assessment». Shpringer, 2009. 353-377 pp. 